\section{Arcobacter spp. in raw milk from vending machines in Piedmont and occurrence of virulence genes in isolates}

\author{
Amaranta Traversa, ${ }^{1}$ Silvia Gallina, ${ }^{1}$ \\ Francesca Martucci, ${ }^{1}$ \\ Cvetelina Boteva, ${ }^{1}$ \\ Elisa Baioni, ${ }^{2}$ Cristiana Maurella, ${ }^{2}$ \\ Laura Chiavacci, ${ }^{2}$ Elisa Benvenuto, ${ }^{1}$ \\ Irene Ferrero, ${ }^{1}$ Elena Ferrero, ${ }^{1}$ \\ Federica Giacometti, ${ }^{3}$ Silvia Piva, ${ }^{3}$ \\ Francesco Chiesa, ${ }^{4}$ \\ Daniela Manila Bianchi, ${ }^{1}$ \\ Andrea Serraino, ${ }^{3}$ Lucia Decastelli ${ }^{1}$ \\ ${ }^{1}$ Food Control and Production Hygiene \\ complex unit, Istituto Zooprofilattico \\ Sperimentale del Piemonte, Liguria e \\ Valle d'Aosta, Torino; ${ }^{2}$ Epidemiology \\ and Epidemiological Observatory com- \\ plex unit, Istituto Zooprofilattico \\ Sperimentale del Piemonte, Liguria e \\ Valle d'Aosta, Torino; ${ }^{3}$ Department of \\ Veterinary Medical Sciences, University \\ of Bologna, Ozzano dell'Emilia; \\ ${ }^{4}$ Department of Veterinary Sciences, \\ University of Torino, Grugliasco, Italy
}

\footnotetext{
Abstract

Arcobacter spp. has been recognized as an emerging foodborne pathogen and a hazard to human health. In the dairy chain, it has been isolated from different sources, nevertheless data on Arcobacter occurrence in raw milk provided by vending machines are few. This study aimed to identify potentially pathogenic Arcobacter spp. in raw milk intended for human consumption sold through vending machines located in Piedmont. In an 8-month period, 37 raw milk samples were collected from 24 dairy farms: $12(32,4 \%)$ were collected directly in farm from bulk tank milk and $25(67,6 \%)$ from vending machines. Eight $(21,6 \%)$ out of the 37 milk samples and $7(29,2 \%)$ out of the 24 dairy farms were positive for Arcobacter spp. by culture examination. Four $(16 \%)$ out of the 25 samples from vending machines and $4(33,3 \%)$ out of the 12 samples from bulk tank milk were positive. All 8 isolates were identified as $A$. butzleri both by MALDI-TOF MS and multiplex end-point PCR. According to the detection of virulence genes, a total of four Patho-types were highlighted: 5 isolates in P-type 1 and only one isolate for each of the P-types 2-3-4. A. butzleri isolates carrying encoding virulence factors genes were iso-
}

lated from raw milk intended for human consumption: these findings strengthen the compulsory consumption after boiling as required by current legislation and suggest the need of enlarging the analytical investigations to other microorganisms not yet included in the food safety criteria.

\section{Introduction}

The Arcobacter genus belongs to the Campylobacteraceae family and includes currently twenty-six species. Bacteria belonging to this genus are ubiquitous in the environment and animals can carry Arcobacter spp. asymptomatically in the gut. Three species, Arcobacter butzleri, A. cryaerophilus and $A$. skirrowii are commonly associated with human disease (Ramees et al., 2017). In industrialized countries the main source of infection for humans is the consumption of raw or minimally processed foods and water (Piva et al., 2017). Recently, Arcobacter spp. has been recognized as an emerging foodborne zoonotic pathogen and a serious hazard to human health (Ramees et al., 2017). Many putative virulence genes have been identified: $c a d F$, $H e c A$ and $c j 1349$ genes are responsible for adhesion, $c i a B$ for invasion, hec $B$, tly $A$ and pldA for lysis of erythrocytes, $\operatorname{irg} A$ for iron acquisition and maintaining of infection and $m v i N$ for peptidoglycan biosynthesis (Douidah et al., 2011; Ramees et al., 2017; Girbau et al., 2015).

In the dairy chain, Arcobacter spp. has been isolated from different sources such as faeces, in-line milk filters, bulk tank milk, cheeses, and processing surfaces (Giacometti et al., 2015).

The aims of the study were to investigate the presence of Arcobacter spp. in raw milk intended for human consumption sold through vending machines located in Piedmont (North-West of Italy) or from bulk tank milk in farms authorized to production of raw milk and to define the occurrence of the virulence genes in isolates.

\section{Materials and Methods}

From November 2017 to June 2018, a total of 37 raw milk samples, which were from 24 dairy farms, located in Piedmont (in Turin and Cuneo provinces), that sell raw milk intended for human consumption through automatic self-service vending machines (Table 1), were tested. Twelve $(32,4 \%)$ raw milk samples were collected directly in the farms from bulk tank milk and $25(67,6 \%)$ milk samples from vending machines (Table 1). Vending machines and
Correspondence: Amaranta Traversa, Istituto Zooprofilattico Sperimentale Piemonte, Liguria e Valle d'Aosta, SC Controllo Alimenti e Igiene delle Produzioni, via Bologna 148, Turin, Italy.

Tel.: +39.011.2686240

E-mail: amarantatraversa@gmail.com

Key words: Arcobacter spp., Raw milk, Vending machine, Virulence genes.

Acknowledgments: The authors would like to thank Rosaria Corvonato and Giovanna Previto for supporting in Arcobacter identification operating procedures.

Contributions: The authors contributed equally.

Conflict of interest: the authors declare no potential conflict of interest.

Funding: This project was funded by the Ministry of Health (Project Code IZS PLV 05/14 RC).

Received for publication: 5 October 2018 Revision received: 8 July 2019

Accepted for publication: 9 July 2019

This work is licensed under a Creative Commons Attribution-NonCommercial 4.0 International License (CC BY-NC 4.0).

(C) Copyright: the Author(s), 2019

Licensee PAGEPress, Italy

Italian Journal of Food Safety 2019; 8:7859

doi:10.4081/ijfs.2019.7859

farms where milk samples were collected are showed in Figure 1. For the detection of Arcobacter spp. the protocol described by Giacometti et al. (2015) was used modifying the isolation step, by using in parallel the selective agar plate supplemented with $10 \%$ laked horse blood and the Campylobacter Blood-Free Selective Agar Base (CCDA - Oxoid). Suspected colonies on the two selective agar, appearing as small and transparent and flat translucent respectively, were subcultured and identified using MALDI-TOF MS (Vitek MS bioMerieux). To test the limit of detection of the protocol, we contaminated raw milk samples with $10^{4} \mathrm{CFU} / \mathrm{mL}, 10^{3} \mathrm{CFU} / \mathrm{mL}$, $10^{2} \mathrm{CFU} / \mathrm{mL}$ and $10 \mathrm{CFU} / \mathrm{mL}$ of $A$. butzleri DSM $8739^{\mathrm{TM}}$ strain; the analysis were performed twice for each contamination level.

Arcobacter species were confirmed using the multiplex PCR end-point described by Douidah et al. (2010). The presence of the nine virulence genes $(\mathrm{cadF}$, pldA, tly $A, \operatorname{cia} B, \operatorname{irg} A$, hecA, mviN, cj1349 and $h e c B$ ) was investigated by multiplex PCR end-point according to Douidah et al. (2011). DNA was extracted from 
Arcobacter isolates using Instagene Matrix (Bio-Rad). A. butzleri DSM $8739^{\mathrm{TM}}$ and $A$. cryaerophilus DSM $7289^{\mathrm{TM}}$ were used as reference strains in both PCR. According to the presence of the virulence genes, isolates were grouped in pathotypes, later labeled as P-types. For the analysis of the results, the two-sample Wilcoxon rank-sum (MannWhitney) tests were performed to compare the proportions of positive samples collected from vending machines to those collected from bulk tank milk and the proportions of positive samples collected in winter to those collected in spring.

\section{Results}

Eight $(21.6 \%)$ out of the 37 raw milk samples were positive for Arcobacter spp.; $4(16 \%)$ out of the 25 samples from vending machines and $4(33,3 \%)$ out of the 12 samples from bulk tank milk were positive. Seven $(29,2 \%)$ dairy farms out of the 24 were positive. Positive sampling sites, both vending machines and bulk tank milk respectively, are showed in Figure 1.

All 8 isolates resulted to be $A$. butzleri both by MALDI-TOF MS and multiplex end-point PCR (Table 2). In dairy farm ID20, A. butzleri was isolated from both vending machine and bulk tank milk samples.

Dealing with the limit of detection, contaminated raw milk samples resulted to be positive for Arcobacter spp. isolation until the $10^{2} \mathrm{CFU} / \mathrm{mL}$ level for both determinations.

The rates of isolation of Arcobacter spp. from vending machines and from bulk tank milk, as well as from winter and from spring resulted to be not significantly different.

The genes ciaB, mniN, tlyA, $p l d A$ and $c a d F$ were detected in all the isolates $(100 \%)$, the gene $c j 1349$ was detected in $87,5 \%$ of the isolates, the gene $h e c B$ in $25 \%$ of the isolates, whereas the genes $h e c A$, and $\operatorname{irg} A$ were detected in only $12,5 \%$ of isolates respectively (Table 2 ). A total of four P-types were highlighted, respectively five isolates in P-type 1 and only one isolate for each of the P-types 2-3-
4. The two A. butzleri strains isolated from dairy farm ID20 showed different P-types: P-type 1 in the strain from vending machine and P-type 3 in the strain from bulk tank milk. Details about the identified species of isolates and the occurrence of the virulence genes are reported in Table 2.

Table 1. Samples collected during this study from vending machines and from bulk tank milk per year.

\begin{tabular}{|c|c|c|c|c|c|}
\hline $\begin{array}{l}\text { Dairy Farm } \\
\text { Id }\end{array}$ & Sampling & 2017 & Sampling sits & & Total \\
\hline & Vending machine & Farm & Vending machine & Farm & \\
\hline $1^{*}$ & 1 & 0 & 2 & 1 & 4 \\
\hline $2^{*}$ & 1 & 0 & 2 & 0 & 3 \\
\hline 3 & 0 & 0 & 0 & 1 & 1 \\
\hline 4 & 0 & 0 & 1 & 0 & 1 \\
\hline 5 & 1 & 0 & 0 & 0 & 1 \\
\hline 6 & 0 & 0 & 1 & 0 & 1 \\
\hline 7 & 0 & 0 & 1 & 0 & 1 \\
\hline 8 & 0 & 0 & 1 & 1 & 2 \\
\hline 9 & 0 & 0 & 1 & 1 & 2 \\
\hline 10 & 1 & 0 & 0 & 0 & 1 \\
\hline 11 & 0 & 0 & 1 & 0 & 1 \\
\hline 12 & 0 & 0 & 0 & 1 & 1 \\
\hline 13 & 0 & 0 & 1 & 0 & 1 \\
\hline 14 & 0 & 1 & 1 & 0 & 2 \\
\hline 15 & 0 & 0 & 0 & 1 & 1 \\
\hline 16 & 0 & 0 & 1 & 0 & 1 \\
\hline 17 & 0 & 0 & 0 & 1 & 1 \\
\hline 18 & 0 & 0 & 0 & 1 & 1 \\
\hline 19 & 0 & 0 & 1 & 0 & 1 \\
\hline 20 & 0 & 1 & 1 & 0 & 2 \\
\hline 21 & 0 & 1 & 0 & 0 & 1 \\
\hline $22^{\wedge}$ & 1 & 0 & 1 & 0 & 2 \\
\hline 23 & 1 & 0 & 1 & 0 & 2 \\
\hline $24^{\wedge}$ & 1 & 0 & 1 & 1 & 3 \\
\hline Total & 7 & 3 & 18 & 9 & 37 \\
\hline
\end{tabular}

*Dairy farms providing more vending machines. ${ }^{\wedge}$ In dairy farm ID22 and ID24, samples were collected from the same vending machine per year.

Table 2. Arcobacter species isolated from raw milk samples intended for human consumption and occurrence of virulence genes in isolates.

\begin{tabular}{|c|c|c|c|c|c|c|c|c|c|c|c|c|c|c|}
\hline \multirow{2}{*}{$\begin{array}{l}\text { Dairy Farm } \\
\text { Id }\end{array}$} & \multirow{2}{*}{$\begin{array}{l}\text { Strain } \\
\text { Id }\end{array}$} & \multirow{2}{*}{$\begin{array}{l}\text { Sampling } \\
\text { Site }\end{array}$} & \multicolumn{2}{|c|}{ Species Identification } & \multirow[b]{2}{*}{ cadF } & \multirow[b]{2}{*}{ pldA } & \multicolumn{5}{|c|}{ Detection of virulence genes - PCR } & \multirow[b]{2}{*}{ cj1349 } & \multirow[b]{2}{*}{ hecB } & \multirow[b]{2}{*}{ P-type } \\
\hline & & & Vitek MS & PCR & & & tlyA & $\operatorname{ciaB}$ & $\operatorname{irg} A$ & hecA & mviN & & & \\
\hline 3 & $46550 / 18$ & BTM & A. butzleri & A. butzleri & + & + & + & + & - & - & + & + & - & 1 \\
\hline 5 & 101112/17 & VM & A. butzleri & A. butzleri & + & + & + & + & - & - & + & + & - & 1 \\
\hline 6 & $46555 / 18$ & $\mathrm{VM}$ & A. butzleri & A. butzleri & + & + & + & + & + & + & + & + & + & 4 \\
\hline 8 & $50147 / 18$ & BTM & A. butzleri & A. butzleri & + & + & + & + & - & - & + & + & - & 1 \\
\hline 20 & $18760 / 18$ & BTM & A. butzleri & A. butzleri & + & + & + & + & - & - & + & - & - & 3 \\
\hline 20 & $101120 / 17$ & VM & A. butzleri & A. butzleri & + & + & + & + & - & - & + & + & - & 1 \\
\hline 21 & $101123 / 17$ & BTM & A. butzleri & A. butzleri & + & + & + & + & - & - & + & + & - & 1 \\
\hline 23 & $106579 / 17$ & $\mathrm{VM}$ & A. butzleri & A. butzleri & + & + & + & + & - & - & + & + & + & 2 \\
\hline
\end{tabular}

VM: vending machine; BTM: bulk tank milk. 


\section{Discussion}

The isolation of Arcobacter spp. from raw cow milk has been reported by various authors with a wide range (between 3.2 and $80 \%$ ), and most of them reported $A$. butzleri as the most frequently identified species (Yesilmen et al., 2014; Scullion et al., 2006; Ramees et al., 2017; Giacometti et al., 2015); our results are in accordance with these data. As reported by many authors, differences in Arcobacter prevalence may be due to many factors as farm management (hygienic conditions, source of water, animal diet) as well as different sampling methods, isolation protocols and also the different type of samples (bulk tank milk, individual cow milk samples, in-line milk filters) (Scullion et al., 2006; Ertas et al., 2010; Serraino et al., 2013).

The ciaB, mviN, tlyA, cj1349, pld $A$ and $c a d F$ genes are mainly implicated in adhesion and invasion mechanisms and are the most frequently detected genes in the present study, with an occurrence higher than reported by Piva et al. (2017) in samples collected from dairy chain but with different scenarios (overall prevalence of $57.5 \%$ ). From different hosts and environments like human stool, food products, processing water, faecal samples, slaughterhouse processing line equipment, the prevalence values ranging from 66 to $100 \%$ (Douidah et al., 2012; Karadas et al., 2013; Ferreira et al., 2014; Tabatabaei et al., 2014; Girbau et al., 2015; Zacharow et al., 2015; Laishram et al., 2016; Mottola et al., 2016). In accordance with the studies of Piva et al. (2017) and Girbau et al. (2015), a low occurrence of hecA, hec $B$ and $\operatorname{irg} A$ genes was observed in dairy isolates whereas in other food sources and food chains a high occurrence of these genes was reported (Karadas et al., 2013; Ferreira et al., 2014; Lehmann et al., 2015; Zacharow et al., 2015; Mottola et al., 2016).

In one dairy farm (ID20) A. butzleri was detected both from vending machine and bulk tank milk, but the two isolates showed different P-types profiles (P-type 1 and Ptype 3 respectively); to note that the two samples were collected from a vending machine in 2017 and from bulk tank milk in 2018 respectively. A. butzleri has been reported to be an environmental microorganism able to survive in adverse conditions thanks to its ability to produce biofilm or to be incorporated in pre-existing biofilms (Giacometti et al., 2015). Faecal contamination should not be considered the main source of Arcobacter spp. in dairy farm, as reported by Giacometti et al. (2015) water is an important route of transmission of Arcobacter both for the animals and the farm environment: different species and genotypes were detected throughout a year surveillance suggesting reinfection of cattle during the observation period.

No significative differences were found between sampling sites (bulk tank milk versus vending machines) and sampling seasons (winter versus spring). Seasonal variations in the prevalence rate of Arcobacter were reported in a water treatment plant in Spain with $92 \%$ prevalence in spring, $83 \%$ in summer and $75 \%$ in winter but, as reported by many other authors, no significant differences were observed (Ramees et al., 2017). In Italy a seasonal association has been reported for A. butzleri in bivalve molluscs samples with a significantly more likely presence during the winter-spring period rather than in the summer-autumn (Leoni et al., 2017). Concerning the sampling sites, no data are currently available, and further samplings were needed to investigate the possible role of sampling site in maintaining $A$. butzleri in the environment.

In Italy, the sale of raw milk through vending machines is authorized by the Italian Ministry of Health and is regulated by an agreement between the state and the regions (Intesa Stato Regioni, 2007). This agreement sets the biosafety measures, the microbiological and chemical criteria for milk, the vending machine installation and management specifications which dairy farms must comply with. Since 2008 the Italian Ministry of Health with subsequent ordinances and the Ministerial Decree 12 December 2012 made it compulsory that all raw milk vending machines carry a warning that the milk should be boiled at home before consumption. Monitoring surveys have been conducted in Piedmont to check that the raw milk sold via vending machines
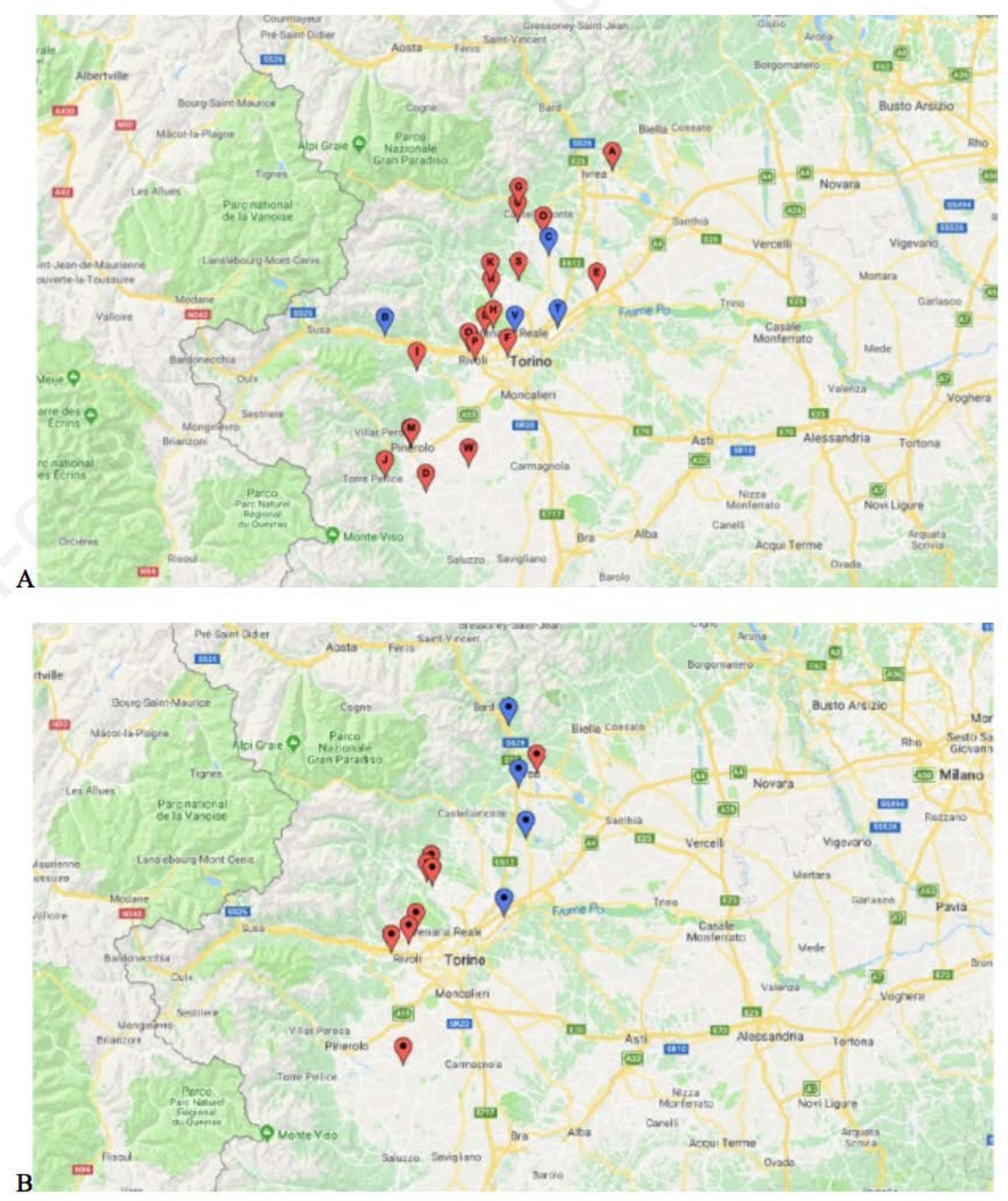

Figure 1. Vending machines (A) and bulk tank milk (B) where milk samples were collected: negative sampling sites (red), positive sampling sites for A. butzleri (blue). 
complies with the criteria of the national regulation; Bianchi et al. (2013) reported the results of a three-year monitoring survey in Piedmont confirming that the unpasteurized milk could be vehicle of a variety of microorganisms and can be an important source of foodborne illness outbreaks, especially if consumers are young, elderly, or ill. The occurrence of $A$. butzleri isolates carrying encoding virulence factors genes underlines once again the importance of respecting the compulsory consumption of vending machine milk after boiling and suggests the need of widening the detection of other microorganisms not yet included in the monitoring plans.

\section{Conclusions}

The milk chain environment can be considered a good ecological niche for $A$. butzleri, a microorganism reported to be able to survive to routine sanitizing procedures and to persist on several processing surfaces. The isolation of this emerging pathogen in raw milk intended for human consumption sold through vending machines strengthens the compulsory consumption after boiling as required by current legislation. Moreover, the detection of A. butzleri in milk suggests the importance of enlarging the analytical investigations to other emerging microorganisms to date not included among the food safety criteria.

\section{References}

Bianchi DM, Barbaro A, Gallina S, Vitale N, Chiavacci L, Caramelli M, Decastelli L, 2013. Monitoring of foodborne pathogenic bacteria in vending machine raw milk in Piedmont, Italy. Food Control 32:435-9.

Douidah L, De Zutter L, Vandamme P, Houf $\mathrm{K}, 2010$. Identification of five human and mammal associated Arcobacter species by a novel multiplex-PCR assay. J Microbiol Meth 80:281-6.

Douidah L, De Zutter L, Baré J, De Vos P, Vandamme P, Vandenberg, O, Van den Abeele AM, Houf K, 2011. Occurrence of putative virulence genes in Arcobacter species isolated from humans and animals. J Clin Microbiol 50:735-41.

Ertas N, Dogruer Y, Gonulalan Z, Guner A,
Ulger I, 2010. Prevalence of Arcobacter species in drinking water, spring water, and raw milk as determined by multiplex PCR. J Food Protect 73:2099-102. Ferreira S, Queiroz JA, Oleastro M, Domingues FC, 2014. Genotypic and phenotypic features of Arcobacter butzleri pathogenicity. Microb Pathogenesis 76:19-25.

Giacometti F, Lucchi A, Di Francesco A, Delogu M, Grilli E, Guarniero I, Stancampiano L, Manfreda G, Merialdi G, Serraino A, 2015. Arcobacter butzleri, Arcobacter cryaerophilus and Arcobacter skirrowii circulation in a dairy farm and sources of milk contamination. Appl Environmental Microbiol 81:5055-63.

Girbau C, Guerra C, MartínezMalaxetxebarria I, Alonso R, Fernández-Astorga A, 2015. Prevalence of ten putative virulence genes in the emerging foodborne pathogen Arcobacter isolated from food products. Food Microbiol 52:146-9.

Karadas G, Sharbati S, Hänel I, Messelhäußer U, Glocker E, Alter T, Gölz G, 2013. Presence of virulence genes, adhesion and invasion of Arcobacter butzleri. J Appl Microbiol 115:583-90.

Intesa Stato Regioni e Province Autonome di Trento e Bolzano - ISR-25th-Jan2007. 2007a.

Laishram M, Rathlavath S, Lekshmi M, Kumar S, Nayak BB, 2016. Isolation and characterization of Arcobacter spp. from fresh seafood and the aquatic environment. Int J Food Microbiol 232:879.

Leoni F, Chierichetti S, Santarelli S, Talevi G, Masini L, Bartolini C, Roccheggiani E, Naceur Haouet M, Ottaviani D, 2017. Occurrence of Arcobacter spp. and correlation with the bacterial indicator of faecal contamination Escherichia coli in bivalve molluscs from the Central Adriatic, Italy. Int J Food Microbiol 245:6-12.

Ministerial Decree 12 December 2012. Informazioni obbligatorie e misure a tutela del consumatore di latte crudo o crema cruda, in attuazione dell'art. 8, commi 6 e 9, del decreto-legge 13 settembre 2012, n. 158, recante "Disposizioni urgenti per promuovere lo sviluppo del Paese mediante un piu' alto livello di tutela della salute" convertito, con modificazioni, dalla legge 8 novembre 2012, n. 189. (13A00727) (GU Serie Generale n.24 del 29-012013).

Mottola A, Bonerba E, Bozzo G, Marchetti P, Celano GV, Colao V, Terio V, Tantillo G, Figuera MJ, Di Pinto A, 2016. Occurrence of emerging food-borne pathogenic Arcobacter spp. isolated from pre-cut (ready-to-eat) vegetables. Int J Food Microbiol 236:33-7.

Piva S, Gariano GR, Bonilauri P, Giacometti F, Decastelli L, Florio D, Massella E, Serraino A, 2017. Occurrence of putative virulence genes on Arcobacter butzleri isolated from three different environmental sites throughout the dairy chain. J Appl Microbiol 122:1071-7.

Ramees TP, Dhama K, Karthik K, Rathore RS, Kumar A, Saminathan M, Tiwari R, Malik YA, Singh RK, 2017. Arcobacter: an emerging food-borne zoonotic pathogen, its public health concerns and advances in diagnosis and control-a comprehensive review. Vet Quart 37: 136-61.

Serraino A, Florio D, Giacometti F, Piva S, Mion D, Zanoni RG, 2013. Presence of Campylobacter and Arcobacter species in in-line milk filters of farms authorized to produce and sell raw milk and of a water buffalo dairy farm in Italy. $\mathrm{J}$ Dairy Sci 96:2801-7.

Scullion R, Harrington CS, Madden RH, 2006. Prevalence of Arcobacter spp. in raw milk and retail raw meats in Northern Ireland. J Food Protect 69: 1986-90.

Tabatabaei M, Aski. S, Shayegh H, Khoshbakht R, 2014. Occurrence of six virulence-associated genes in Arcobacter species isolated from various sources in Shiraz, Southern Iran. Microb Pathogenesis 66:1-4.

Zacharow I, Bystroń J, Wałecka-Zacharska E, Podkowik M, Bania J, 2015. Genetic diversity and incidence of virulenceassociated genes of Arcobacter butzleri and Arcobacter cryaerophilus isolates from pork, beef, and chicken meat in Poland. BioMed Res Int 956507.

Yesilmen S, Vural A, Erkan ME, Yildirim IH, 2014. Prevalence and antimicrobial susceptibility of Arcobacter species in cow milk, water buffalo milk and fresh village cheese. Int $\mathrm{J}$ Food Microbiol 188:11-4. 